\title{
THE USE OF PARTICLE IMAGE VELOCIMETRY FOR DISPLACEMENT MEASUREMENTS IN STEEL COLUMNS SUBJECTED TO BUCKLING
}

\author{
Maykmiller Carvalho Rodrigues \\ Federal University of Lavras (UFLA), Engineering Dept., CP3037, CEP37200-000, Lavras, MG, Brazil \\ Corresponding author: maykmiller.rodrigues@deg.ufla.br

\section{Francisco Carlos Gomes} \\ Federal University of Lavras (UFLA), Engineering Dept., CP3037, CEP37200-000, Lavras, MG, Brazil
}

\author{
Roberto Alves Braga Jr. \\ Federal University of Lavras (UFLA), Engineering Dept., CP3037, CEP37200-000, Lavras, MG, Brazil \\ Fernando Pujaico Rivera \\ Federal University of Lavras (UFLA), Engineering Dept., CP3037, CEP37200-000, Lavras, MG, Brazil
}

\author{
Ricardo Rodrigues Magalhães \\ Federal University of Lavras (UFLA), Engineering Dept., CP3037, CEP37200-000, Lavras, MG, Brazil
}

\author{
Jéssica Assaid Martins Rodrigues \\ Federal University of Lavras (UFLA), Engineering Dept., CP3037, CEP37200-000, Lavras, MG, Brazil
}

\begin{abstract}
Displacements in structural columns have many challenges regarding to monitoring since it is a complex phenomenon. The monitoring of steel column subjected to buckling is one challenge in order to identify its structural behavior based on displacement measurements. In some cases, this effect is studied under steel rectangular column subjected to axial compressive loads. It is necessary in order to quantify the horizontal column deformation by using optical techniques based on displacements from images to evaluate its structural behavior. This paper is aimed to apply the Particle Image Velocimetry (PIV) technique as a robust and cheap optical method on buckling study of columns as a contactless measurement technique compared to Finite Element Method (FEM). Experiments using rectangular bar samples were used to evaluate the behavior of columns under axial compressive load causing the buckling effect. In order to quantify displacements, PIV technique was applied based on pre-defined positions of the points in the images and the column displacements were measured and compared to FEM. Results indicated displacements difference around 1.08\% between PIV and FEM, providing that PIV technique can be used to quantify column displacements in a plane when compared to FEM results. This allows PIV applications for any structures monitoring such as building, bridges and silos.
\end{abstract}

Index terms: Structural monitoring, displacements, contactless measurements.

Received: April 11, 2018 - Accepted: May 11, 2018

\section{INTRODUCTION}

Columns are structural elements which are subject primarily to the axial normal stresses. Without them, it would not be possible to raise a metallic roof, a multistory building, a bridge or even a metal silo, among other structures (Calil Jr. et al. 1996). The continued development of techniques and tools can seek improvements in the design and monitoring of service structures (Zhao and Teng, 2004; Sadowski and Rotter,
2011). One of the main topics for studying columns is the effect of buckling (ABNT, 2004; ABNT, 2008; Wang et al. 2017; Wang et al. 2018). Buckling effects limit the column resistance and it is known as the lateral displacement produced by compressive forces (Sadowski and Rotter, 2012). In order to study buckling in compressed parts (columns), destructive and nondestructive testing, conventional simulating methods, and structural analysis by finite element technique may be used (Pinheiro, 2005). 
One of the most common destructive test produce some marks in the sample which is being tested under specific loads. This kind of test may be performed by tensile, compression, shear, bending, flexion, cupping, twisting, hardness, creep, fatigue and impact where a universal testing machine, measuring equipment, data acquisition and processing system are often used. Among the methods for contactless measurement tests, ultrasound and $x$-ray are used to validate the results obtained from destructive tests which are used for modeling techniques in the structures behavior simulation. Apart from these already established methods, the Particle Image velocimetry (PIV) technique, initially adopted as a displacement study method of fluid particles (Soares, 2013), is currently being used in the study of solid materials (Petersson, 2010; Souza, 2014). This technique is based on pairwise image correlation obtained from Equation 1.

$C(x, y)=\sum_{i=-M}^{M} \sum_{J=-N}^{N} I_{1}(i, j) I_{2}(i+x, j+y)$

where the result of the pixel coordinate difference and the position change of the points in a estimated window shows the displacement that the $I(i, j)$ is the luminous intensity at the pixel coordinates $(i, j)$ and indices 1 and 2 indicate the images analyzed.

The use of PIV and other optical measurement techniques as a contactless measurement test based on the structure mechanics has being proposed (Braga Jr. et al. 2015; Lei et al. 2016; Magalhaes et al. 2015; Zhang et al. 2012). Assuming that PIV technique can also be used for displacement measurements of steel columns, the aim of this paper is to evaluate PIV technique in rectangular tubular metal profile columns subject to buckling during compression tests.

\section{MATERIAL AND METHODS}

A universal testing machine UTM (AROTEC, WDW - 30OE model, 30 ton) was used to apply the load and the boundary conditions for the experiments. Samples were chosen according to the buckling coefficient for bending isolated elements defined by NBR8800 (ABNT, 2008), used for embedded and labeled bars, Figure 1. The coefficient of buckling adopted was $\mathrm{k}=0.7$.

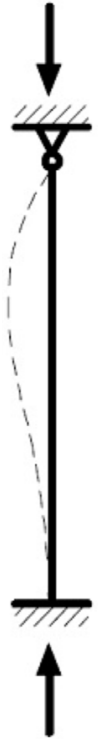

Figure 1: Samples boundary conditions clamped to the universal testing machine.

Twenty samples were chosen for the experiments. Marks and its position were provided in the samples to carry out PIV procedures. Size and positons of the plotted particles on the sample were obtained according to previous tests to evaluate the maximum column displacements. Mechanical tests were performed using a structural steel ASTM A36 material, which was manufactured in rectangular tubular profile with $20 \times 30 \mathrm{~mm}$ cross section, thickness of $1.2 \mathrm{~mm}$ and length of $500 \mathrm{~mm}$, Figure 2.
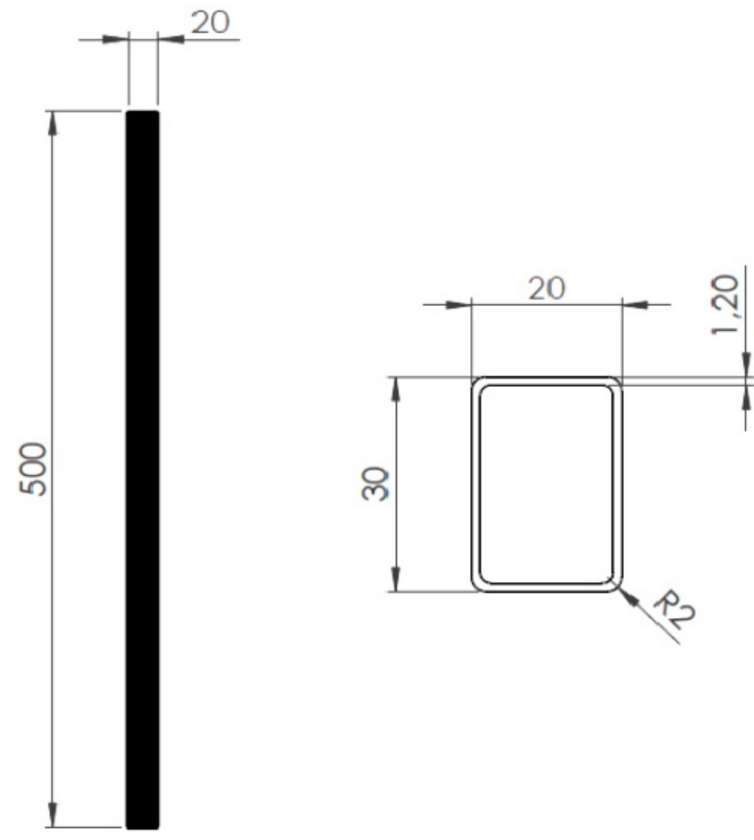

Figure 2: Sample details for the PIV technique evaluation. 
Rectangular samples were adopted with parallel faces (sides) and constant moment of inertia which predicted the occurrence of local buckling. Local buckling could occur in profiles I, C, G and Z and interfere in the PIV results, because the deformation out of the working plane, that causes wrong infect based on the distance from the camera to the sample.

The samples were painted in white paint and equidistant marked points with sizes of $0.5,1.0$, 2.0 and $3.0 \mathrm{~mm}$ and they were defined as reference to the image analysis. Pre-defined marks positions were provided in the region of interest (maximum column displacement prediction). Four sample of each arrangement were analyzed for running the PIV algorithm. The positions of the marks were defined as aligned or not aligned, Figure 3.

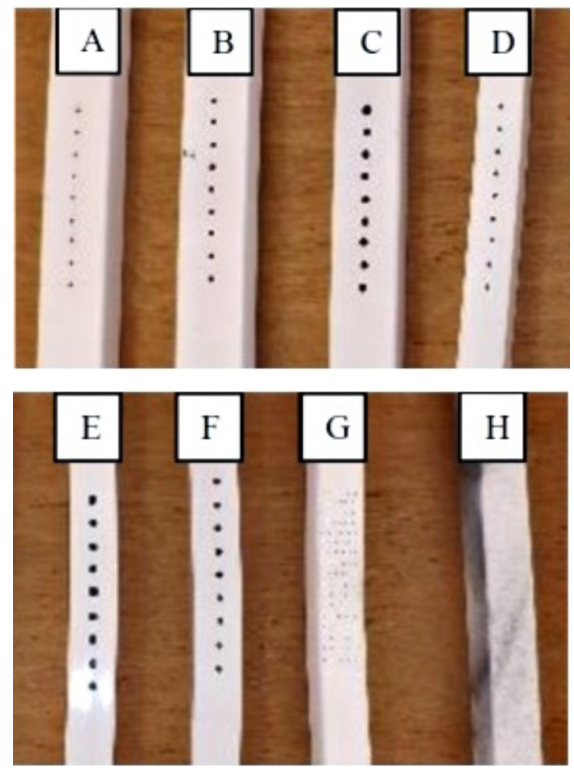

Figure 3: Details (distance and size) of the marks on the samples.

Legend: (A) $1.0 \mathrm{~mm}$ aligned on the face of greater inertia, (B) $2.0 \mathrm{~mm}$ aligned on the face of greater inertia (C) $3.0 \mathrm{~mm}$ aligned on the face of greater inertia, (D) $1.0 \mathrm{~mm}$ points on the face of lower inertia, (E) $3.0 \mathrm{~mm}$ on the face of lower inertia, (F) $2.0 \mathrm{~mm}$ on the face of lower inertia, $(\mathrm{G}) 1.0 \mathrm{~mm}$ on both sides, $(\mathrm{H})$ Steel filings applied throughout the sample.

In order to record the movement of the column, a high-resolution digital camera (CANON EOS 400D) was positioned $250 \mathrm{~mm}$ from the column under compression. Captured images ensured that displacements of the column were accurately recorded during the test. Figure 4 shows the camera position scheme.

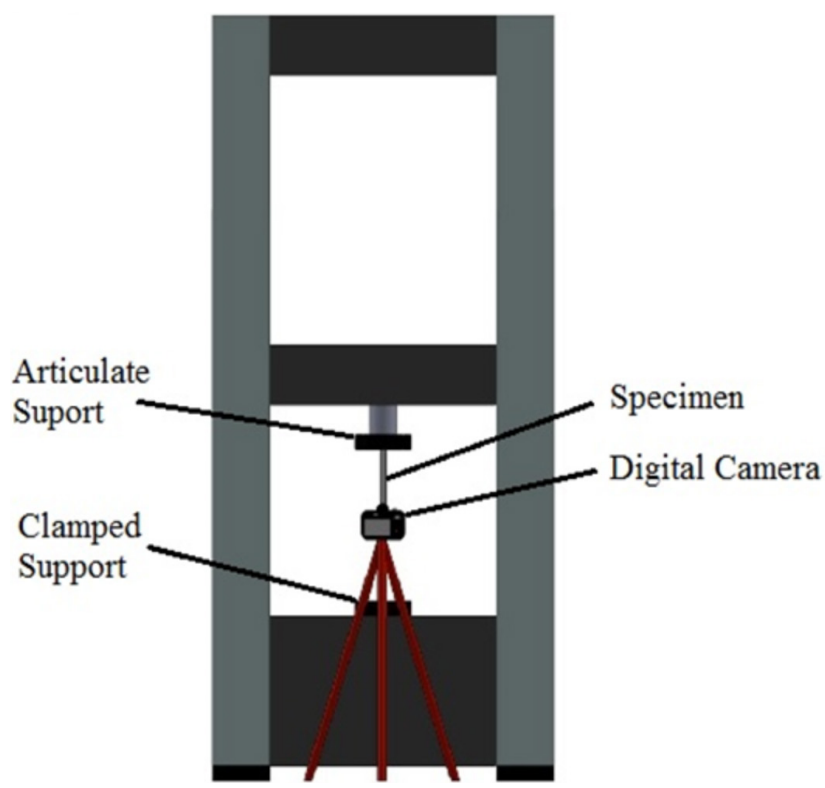

Figure 4: Camera position scheme in relation to the samples.

An image was collected at baseline $\left(t_{0}\right)$, when the sample was not subjected to the load. After starting the test, the compressive load was gradually applied in order to record the maximum displacement of the column before rupture. During the application loads, images were taken at intervals of 10 seconds, resulting in a total of twenty tree images which illustrated the deformation of the sample until its collapse.

Images were processed in an open source software ImageJ, being resized and converted into 8 bits image quality. A threshold was applied to turn the images to black and white, stored in RGB format and analyzed in

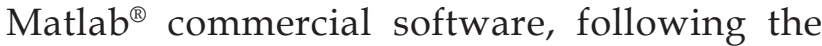
script of standards and PIV programming that provided the displacements results. Figure 5 illustrates the imaging processes performed by the software ImageJ.

PIV displacement results were compared to FEM analysis. FEM simulations were performed using the same sample boundary conditions as the mechanical tests. A commercial FEM solver SolidWorks ${ }^{\circledR}$ was used to model the sample. Solid element type (20 nodes per element) has been chosen, that generated 8636 elements and 17322 nodes. As the solver works with many types of simulation, the bucking analysis was chosen to simulate the numerical analysis. 


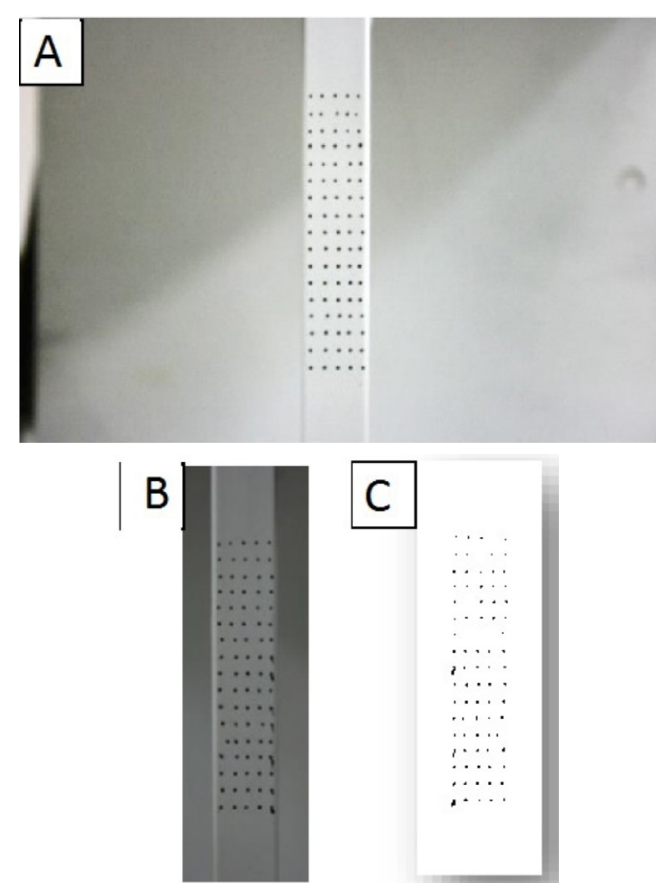

Figure 5: Image treatment on ImageJ software: (A) extracted image of the camera (B) Cropped Image, (C) image in RGB format 8 bit with the application of black and white threshold.

\section{RESULTS AND DISCUSSION}

From the arrangements of evaluated marks in the samples, it was noted that the points must have a minimum spacing between each other and defined sizes in order to provide a better correlation for the comparison of successive images. It was also noted that the marks arrangement in the samples must follow diameters around $1.0 \mathrm{~mm}$ spaced 2.0 $\mathrm{mm}$ and $3.0 \mathrm{~mm}$ between them. Figures $6 \mathrm{~A}$ and $6 \mathrm{~B}$ show marks definition and displacement vectors generated by the deformation of the column during axial compression testing. All vector (Fig. $6 \mathrm{~B})$ are showed in the same print to emphasize the different slopes.

Other points arrangements (Figure 3) did not generate well-defined displacement vectors and they generated inconsistent results in the PIV analysis. Figure 7 represents displacement vectors from different kinds of markings.

Figure 8A and 8B represent displacements results by using PIV technique and FEM analysis, respectively. Results indicated displacement values difference around $1.08 \%$ between PIV and FEM, showing that PIV technique can be used to quantify column displacements, since FEM is a consolidated method for this purpose.

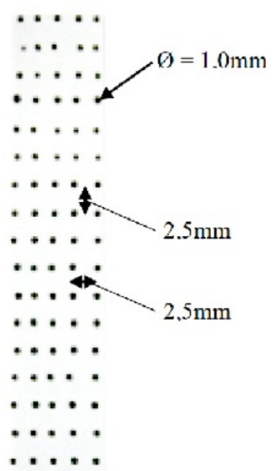

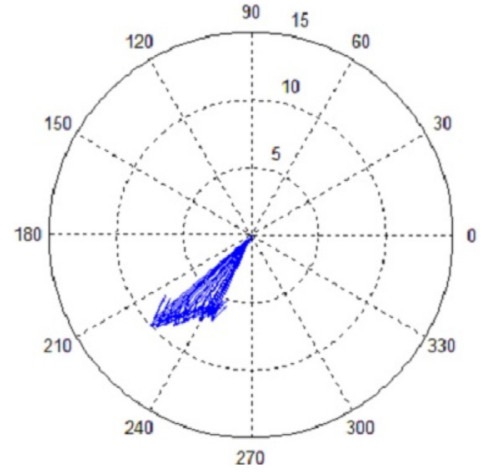

Figure 6: (A) Arrangements and dimensions of the marks on the sample face of lower inertia and (B) displacement vectors from the PIV technique.

A
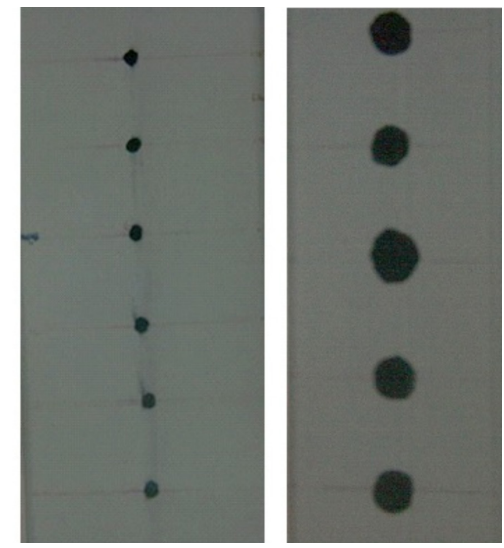

B

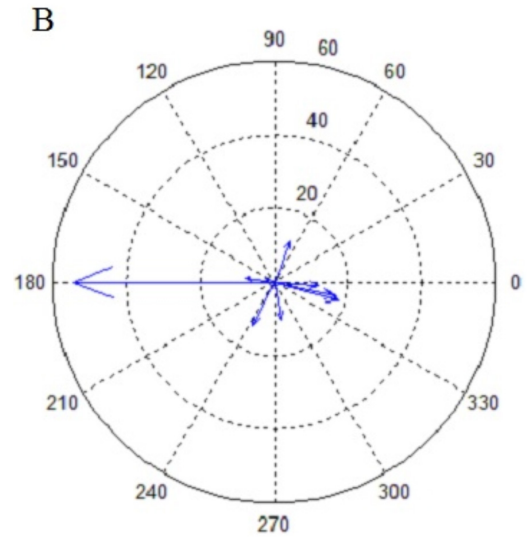

Figure 7: Boundaries and vectors (A) widely spaced markings and diameter greater than $2 \mathrm{~mm}$, (B) Vectors obtained by widely spaced markers and diameter above $2.0 \mathrm{~mm}$.

It is noted in Figure 8 that PIV analysis presented maximum displacement around $1.57 \mathrm{~mm}$ while FEM shows maximum displacement around $1.56 \mathrm{~mm}$, considering the buckling conditions. Figure 9 shows the correlation between vector images design found by FEM analysis and PIV technique, respectively. 

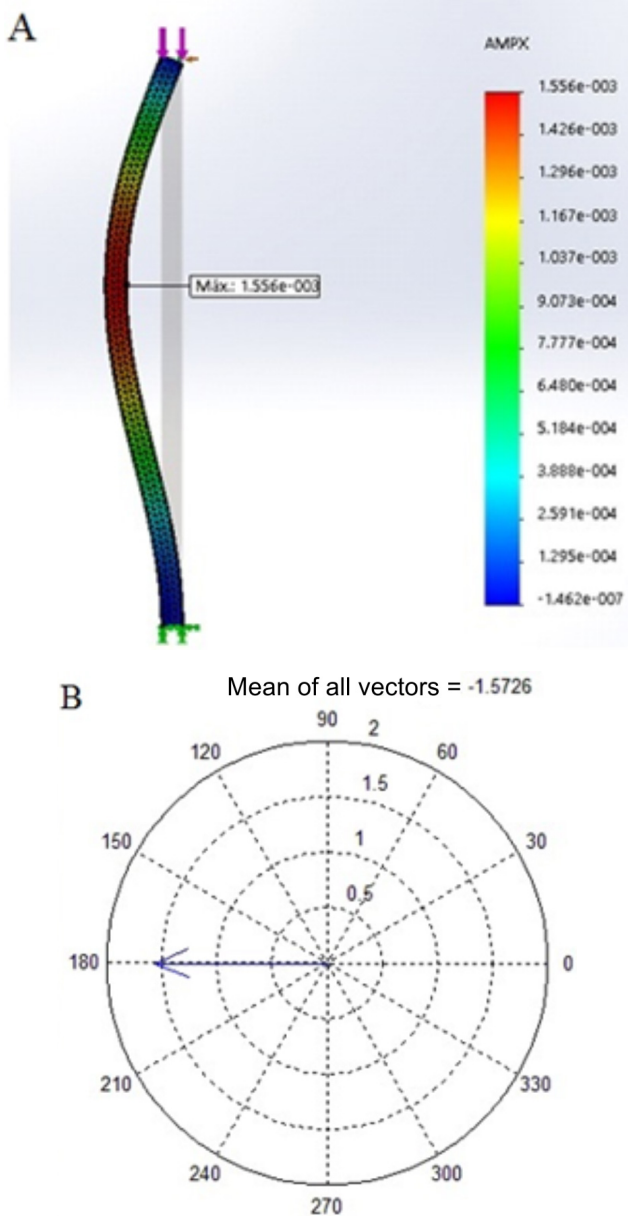

Figure 8: Buckling displacement using (A) FEM and (B) PIV.

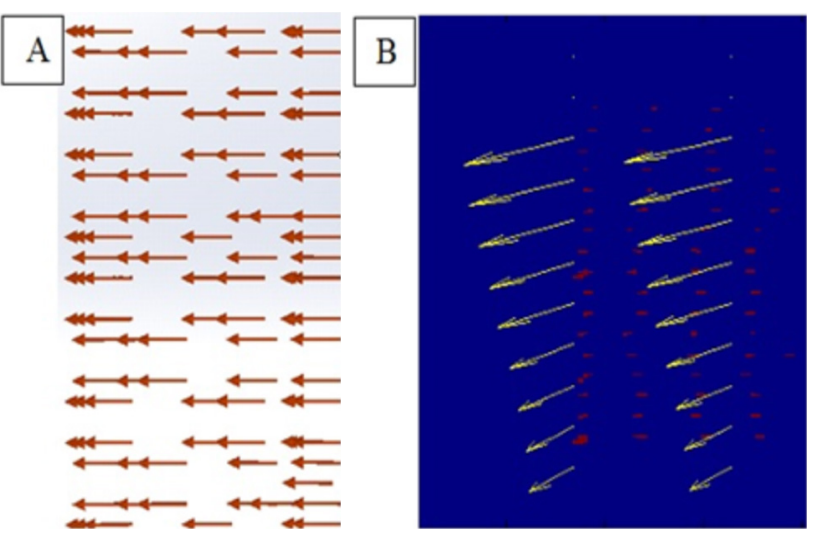

Figure 9: Vector images found in (A) FEM analysis and (B) PIV technique.

\section{CONCLUSIONS}

Particle Image Velocimetry technique associated with marks in a column generated twodimensional deformation vectors in the region of interest, which describe the displacement of the column during the test.
Marks with diameters around $1.0 \mathrm{~mm}$ spaced $2.0 \mathrm{~mm}$ and $3.0 \mathrm{~mm}$ between them showed good correlation in terms of displacements by using PIV technique, which described the column buckling behavior during the compression tests.

Large marks in the samples with high distance between them generated vector dispersions did not represent the behavior of the sample subjected to buckling effect.

Displacements error around $1.08 \%$ between PIV and FEM was found, providing that PIV technique can be used to quantify column displacements in a plane based on pre-defined positions of points in a steel bar when compared to the FEM results, allowing its application for many structures monitoring such as buildings, bridges and silos.

\section{REFERENCES}

ASSOCIAÇÃO BRASILEIRA DE NORMAS TÉCNICAS. NBR 8681: ações e segurança nas estruturas: procedimento. Rio de Janeiro. 2004. 15p.

ASSOCIAÇÃO BRASILEIRA DE NORMAS TÉCNICAS. NBR 8800: projeto de estruturas de aço e de estruturas mistas de aço e concreto de edifícios. Rio de Janeiro. 2008. 15p.

BRAGA JR., R. A. et al. Maps of deformations in a cantilever beam using particle image velocimetry (PIV) and speckle patterns. Revista Escola de Minas, 68:(3)273-278, 2015.

CALIL JR., C. et al. Cylindrical steel silos: study of cases of deformation. Powder Handling \& Processing, 8(2):147-151, 1996.

LEI, Z. et al. Optical measurement on dynamic buckling behavior of stiffened composite panels under in-plane shear, Optics and Lasers in Engineering, 87:111-119, 2016.

MAGALHAES, R. R.; BRAGA JR, R. A.; BARBOSA, B. H. G. Young's modulus evaluation using particle image velocimetry and finite element inverse analysis. Optics and Lasers in Engineering, 70:33-37, 2015.

PETERSSON, H. Use of optical and laser scanning techniques as tools for obtaining improved fe-input data for strength and shape stability analysis of wood and timber. In: European Conference on Computational Mechanics. Paris. Anais. Paris: ECCM, 2010. 
PINHEIRO, A. C. F. B. Estruturas metálicas: Cálculos, Detalhes, Exercícios e Projetos. 2. ed. São Paulo: EdgardBlücher, 2005. 316p.

SADOWSKI, A. J.; ROTTER, J. M. Steel silos with different aspect ratios: I - behavior under concentric discharge. Journal of Constructional Steel Research, 67:1537-1544, 2011.

SADOWSKI, A. J.; ROTTER, J. M. Structural behavior of thin-walled metal silos subject to different flow channel sizes under eccentric discharge pressures. Journal of Structure Engineering, 138:(7)922-931, 2012.

SOARES, R. R. et al. Biospeckle PIV (Particle Image Velocimetry) for analyzing fluid flow. Flow Measurement and Instrumentation, 30:90-98, 2013.

SOUZA, T. M. et al. Non-destructive technology associating PIV and sunset laser to create wood deformation maps and predict failure. Biosystems Engineering, 126:109-116, 2014.

ZHANG, X. et al. Digital image correlation using ring template and quadrilateral element for large rotation measurement. Optics and Lasers in Engineering, 50:(7)922-928, 2012.

ZHAO, Y.; TENG, J. G. Buckling experiments on steel silo transition junctions I: Experimental results. Journal of Constructional Steel Research, 60(12):1783-1801, 2004.

WANG, Z. X. et al. Experimental investigation and parametric analysis on overall buckling behavior of large-section aluminum alloy columns under axial compression. Thin-Walled Structures, 122:585-596, 2018.

WANG, Y. Q. et al. Compressive buckling strength of extruded aluminium alloy i-section columns with fixed-pinned end conditions. Thin-Walled Structures, 119:396-403, 2017. 